\title{
Trichomoniasis in Pregnant Sudanese Pregnant Women at Tertiary Obstetric Facility, Khartoum, Sudan
}

\author{
Hanan A. O. Abd Allha1, A. Fazari1,2,3*, Khalid Y. M. Ahmed ${ }^{4}$ \\ ${ }^{1}$ Reproductive and Child Health Research Unit, University of Medical Sciences \& Technology, Khartoum, Sudan \\ ${ }^{2}$ Omdurman Maternity Hospital, Ministry of Health, Khartoum, Sudan \\ ${ }^{3}$ Latifa Hospital Dubai Health Authority, Dubai, UAE \\ ${ }^{4}$ Faculty of Medicine Alnileen University, Khartoum, Sudan \\ Email: *atiffazari@hotmail.co.uk
}

Received 18 July 2016; accepted 5 August 2016; published 8 August 2016

Copyright (C) 2016 by authors and Scientific Research Publishing Inc.

This work is licensed under the Creative Commons Attribution International License (CC BY).

http://creativecommons.org/licenses/by/4.0/

c. (i) Open Access

\begin{abstract}
Background: Trichomoniasis is a common Sexually Transmitted Disease (STD) and the most common curable one. Methodology: This was cross sectional, prospective, total coverage hospital based study. It aimed to determine the incidence, risk factors of the Trichomoniasis among the laboring Sudanese women at Omdurman New Hospital Khartoum-Sudan, from September 2012 to April 2013. Data were obtained, entered and analyzed using soft word package program for social science (SPSS) version 17. Results: The prevalence of Trichomoniasis is $6.8 \%$. It was found that the awareness about the infection is very low only $35 \%$. Diabetes and history of sexual transmitted infections are the risks seen among the study cases. Preterm labor was seen significantly. Conclusion: Syndromic management of all women with abnormal vaginal discharge is important since it causes reproductive morbidity.
\end{abstract}

\section{Keywords}

Trichomoniasis, Low Birth Weight, Preterm Labor

\section{Introduction}

Trichomoniasis is a common Sexually Transmitted Disease (STD) and the most common curable one. It is caused by the protozoan Trichomonas vaginalis, and affects approximately 180 million persons per year world-

*Corresponding author.

How to cite this paper: Abd Allha, H.A.O., Fazari, A. and Ahmed, K.Y.M. (2016) Trichomoniasis in Pregnant Sudanese Pregnant Women at Tertiary Obstetric. Open Journal of Obstetrics and Gynecology, 6, 539-543.

http://dx.doi.org/10.4236/ojog.2016.69069 
wide. A high prevalence of Trichomonas vaginalis among adult in eastern and Southern Africa, ranges from $17 \%$ to $42 \%$ [1] [2].

\section{Literature Review}

\section{Clinical Features}

The most common presenting complaint among women diagnosed with Trichomonas vaginalis in acute cases is abundant, foamy, yellowish mucopurulent discharge, in more than $50 \%$ of cases. Although $25 \%-40 \%$ of women are asymptomatic [3]. Trichomoniasis has been associated with bacterial vaginosis and cervical cancer, when there is co-infection with HumanPapilloma Virus (HPV).

Most of the men if not all are asymptomatic, infected men may temporarily have urethral irritation, mild discharge, or slight burning after urination or ejaculation. Many men clear Trichomonas vaginalis from the genitourinary tract within 2 weeks. Anyhow less is known about T. vaginalis infection in men. Many studies found that Trichomoniasis during pregnancy shown to produce both vaginal and systemic immune response and is associated with adverse outcome (e.g. history of stillbirth and infant death) [4].

Diagnosis: Diagnosis of Trichomoniasis is suspected from the history and clinical presentation, positive $10 \%$ $\mathrm{KOH}$ (Whiff test) and vaginal $\mathrm{pH}>4.5$ and will be confirmed by microscopic examination, culture on liquid medium, and Polymerase Chain Reaction (PCR). The most common means of diagnosis is visualization of the motile trichomonads in a saline preparation of the vaginal fluid. Currently, the "gold standard" for the diagnosis of Trichomoniasis is culture.

Treatment: Metronidazole is the only efficacious antibiotic for the treatment of Trichomoniasis. The recommended dose is $2 \mathrm{~g}$ orally in a single dose, and the reported cure rate is $97 \%$, or $500 \mathrm{mg}$ twice per day for seven days [5]. Sexual partner should also be treated. Tinidazolemay be a good option for patients with infection resistant to Metronidazole but not recommended in pregnancy, the outcome during pregnancy is uncertain [6].

Complications: Trichomoniasis also may affect the pregnancy outcome causing preterm rupture of membranes, preterm birth by $30 \%$, increase risk of low birth weight and increases risk of HIV infection and transmission [5] [7]. Trichomoniasis associated with urethritis, vaginitis, cervicitis, pelvic inflammatory disease and tubal infertility [8]. It causes serious neonatal eye infection.

Methodology: This was cross sectional, prospective, total coverage hospital based study;it aimed to determine the incidence, risk factors of the Trichomoniasis among the laboring Sudanese women at Omdurman New Hospital Khartoum-Sudan, from September 2012 to April 2013. This is governmental specialized teaching hospital for Obstetrics and Gynecology services with annual registration of $(12,350)$ deliveries.

All women attending the labor ward during the period of study were enrolled in this study lucky enough none is refuse to participate. Urine analysis was done for every woman in the labor wards on their arrival. The motility test is use as it is easy, simple and cheap test to see the $T$. vaginalis. The tests like culture and polymerase chain reaction are time consuming and costly.

Data were collected using specific data collecting sheet designed for this purpose.

The data were entered, analyzed using Statistical Package for Social Sciences (SPSS) data analysis tool, Version 17 facilities.

The study was approved and ethical clearance was obtained from the Ethical Committee at the University of Medical Sciences \& Technology; as well agreement was signed from the medical director of the Hospital. Inform verbal consent was obtained from cases. The confidentiality was granted through and after the study.

\section{Results}

During the period of the study the Omdurman New Hospital served 11,521 cases, out of them 3145 were registered deliveries. We report 214 cases of Trichomonasvaginalis, which gives prevalence of $6.8 \%$. The main affected age group was 20 - 24 years represented 39.3\%, seen in Figure 1. Most of the cases concerning their residency were from urbanarea almost two third of the cases $=66.8 \%$. The rest came for delivery from rural areas $33.2 \%$.

With respect to the parity $41.1 \%$ cases are primiparous at time of the diagnosis, similar percentage for the multiparous women, but the grandmultipara cases are $17.8 \%$.

Only $3.7 \%$ of the study group had history of diabetes as chronic medical disease risk for such vaginal 


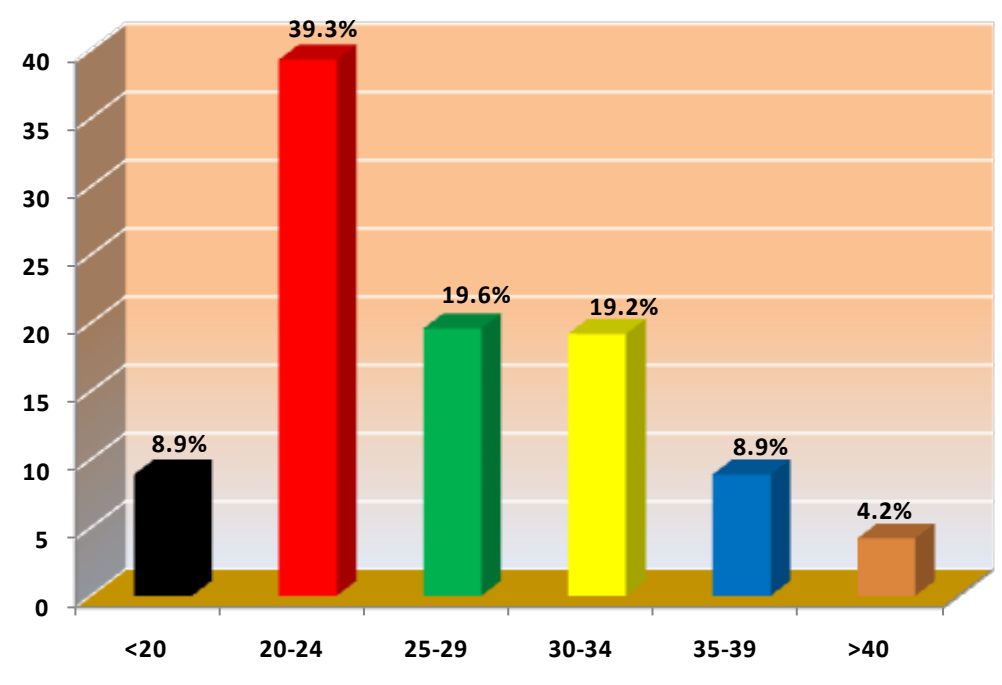

Figure 1. Shows the age distribution among the study group. $(\mathrm{N}=214)$.

infection, while 31 cases $=14.5 \%$ of the study cases gave history of sexual transmitted infections and received treatment. Being a wife of husband with another wife risks her for Trichomoniasis as this seen in $28 \%$ of the cases.

Unfortunately the majority of women are not aware of the disease $65 \%$ only $35 \%$ had some knowledge about STI (know about vaginal discharge, abnormal smell and vulval itching).

Although all the 214 cases were proved to have the infection only $18.7 \%$ were symptomatic the rest $81.3 \%$ showed no symptom.

The frequency of the preterm labor was seen among 31 cases (14.5\%) of the study cases is high with significant statistical weight (Table 1).

In Table 2; the low birth neonates are 16 neonates, three of their mothers gave history of Trichomoniasis.

\section{Discussion}

Sudan has high burden of reproductive health issues; sexually transmitted infections is one of the major challenges that increase the affect on reproductive morbidity.

Consistent with other research the affected age group is the younger population who are at risk for sexually transmitted infections. In a study from Brazil the mean affected age is 25 years [9].

Diabetes mellitus is diagnosed among $3.7 \%$. One of the limitations of this study is that multiple pregnancies and diabetic women were not excluded.

The prevalence of Trichomoniasis is $6.8 \%$ more or less almost like that seen in study done in Upper Egypt the prevalence was $8.7 \%$ [10] and far less than what proved in study done in Lagos, Nigeria found that the prevalence is high $74.5 \%$. Trichomoniasis is reported to be low among the Muslim population in comparison to nonMuslimgroups in India, due to conservative life style [11] and it is not a case here in our study.

In our study the history of sexual transmitted infections and received treatment was $14.5 \%$ compared to $25 \%$ in a study in Zimbabwe [12].

In our study sixty five (65\%) of the Trichomoniasis cases are not aware about sexual transmitted infections (STIs). This is coupled with lack of education surrounding STIs and stigma and un-enabling cultural life styles (e.g. low condom use, feeling ashamed, low care seeking behavior).

Treatment of Trichomoniasis is important, as it reduces the risk of preterm delivery. Syndromic patient treatment cover gonorrhea, Chlamydia, Bacterial vaginosis and Candida albicans, but Syndromic treatment will lead to over treatment [13].

Trichomoniasis is associated with high risk of HIV transmission, in a study done in Mombasa, Kenya they found that Trichomoniasis was associated with a 1.52-fold (95\% confidence interval, 1.04 - 2.24-fold) increase risk of HIV-1 acquisition, treatment and prevention of T. vaginalis infection could reduce HIV-1 risk women. [14]. 
Table 1. The ratio preterm and term delivery and Trichomonas vaginalis infection ( $P$ value $=0.027)$.

\begin{tabular}{cccccc}
\hline & & \multicolumn{2}{c}{ Delivery } & & Total \\
\cline { 3 - 5 } & & & Preterm & Term & 214 \\
T.V & Positive & 31 & 183 & 2931 \\
& Negative & 287 & 2644 & 3145 \\
\hline
\end{tabular}

Table 2. The Trichomonas vaginalis infection and low birth weight $(P$ value $=0.192)$.

\begin{tabular}{|c|c|c|c|c|}
\hline & & \multicolumn{2}{|c|}{ Birth weight } & \multirow{2}{*}{ Total } \\
\hline & & Low & Normal & \\
\hline \multirow{2}{*}{ T.V } & Positive & 16 & 198 & 214 \\
\hline & Negative & 176 & 2755 & 2931 \\
\hline Total & & 192 & 2953 & 3145 \\
\hline
\end{tabular}

$14.5 \%$ of the women with Trichomoniasis in our study had preterm labor with statistically significant association $P$ value (0.027). The others causes of preterm labor (e.g. other infection, high blood pressure, early induction of labor, caesarean section, multiple pregnancy and spontaneous occurrence) were already excluded and not found here.

$7.5 \%$ of study pregnant women' neonates with low birth weight, $P$ value is $(0.192)$, without significant association.

\section{Conclusions}

Apart from women cultural behaviors affecting their sexual-reproductive health the time constrains at the facilities make it difficult to perform confirmatory tests for Trichomonas vaginalis like culture and polymerase chain reaction. Therefore treating STIs and other vaginal infections is difficult while they are of great public health importance.

The study has several mentioned limitations influencing the validity to detect of the statistically significant correlations between Trichomoniasis \& preterm delivery.

\section{Recommendation}

Syndromic case management for STIs and other vaginal infections during pregnancy is recommended especially for those who at risk. Increase the awareness towards the STIs protection, treatment and follow up at community level is important in STIs management. Neonatal care after delivery among the infected women as preterm and low birth weight both are serious neonatal risks. More researches and studies should be carried with control group to come out with the detailed statistical data for further planning and guidance between etiologic, clinical and Syndromic case management.

\section{Discloser}

Nothing to be disclose and no conflict of interest.

\section{References}

[1] Perazzi, B., Menghi, C. and Famiglietti, R. (2010) Prevalence and Comparison of Diagnostic Methods for Trichomonas vaginalis Infection in Pregnant Women in Argentina. Korean Journal of Parasitology, 48, 61-65. http://dx.doi.org/10.3347/kjp.2010.48.1.61

[2] Cook, G.C. (2010) Alimuddin I Zumla.Tropical Diseases, Ch. 81, 1421-1423.

[3] Gulmezoglu, A.M. (2002) Interventions for Trichomoniasis in Pregnancy. Cochrane Database of Systematic Reviews, 


\section{3, CD000220. http://dx.doi.org/10.1002/14651858.cd000220}

[4] Majeroni, B. and Ukkadam, S. (2007) Screening and Treatment for Sexually Transmitted Infection in Pregnancy. American Family Physician, 76, 265-270.

[5] Anderson, B.L., Cosentino, L.A., Simhan, H.N. and Hillier, S.L. (2007) Systemicimmune Response to Trichomonas vaginalis Infection during Pregnancy. Sexually Transmitted Diseases, 34, 392-396.

[6] Fonseca, T.M.V., César, J.A., Hackenhaar, A.A., Ulmi, E.E. and Neumann, N.A. (2008) Corrimento vaginal referido entre gestantesemlocalidade urbana no sul do Brasil: Prevalência e fatoresassociados. Cadernos de Saúde Pública, 24, 558-566. http://dx.doi.org/10.1590/S0102-311X2008000300009

[7] Buve, A., Weiss, H.A., Laga, M., et al. (2001) The Epidemiology of Trichomoniasis in Women in Four African Cities. AIDS, 15, S89-S96. http://dx.doi.org/10.1097/00002030-200108004-00010

[8] Price, M.A., Zimba, D., Hoffman, I.F., Kaydos-Daniels, S.C., Miller, W.C. and Martinson, F. (2003) Addition of Treatment for Trichomoniasis to Syndromic Management of Urethritis in Malawi: A Randomized Clinical Trial. Sexually Transmitted Infections, 30, 516-522. http://dx.doi.org/10.1097/00007435-200306000-00009

[9] Gondo, D., Duarte, M., Silva, M. and Parada, C. (2010) Abnormal Vaginal Flora in Low Risk Pregnant Women Cared for by a Public Health Service, Prevalence and Association with Symptoms and Finding from Gynecological Examination. Revista Latino-Americana de Enfermagem, 18, 919-927. http://dx.doi.org/10.1590/S0104-11692010000500012

[10] Sullam, S.A., Mahfouz, A.A., Dabbous, N.I., El-Barrawy, M. and El-Said, M.M. (2001) Reproductive Tract Infection among Married Women in Upper Egypt. Eastern Mediterranean Health Journal, 7, 130-146.

[11] Anorlu, R.I., Fagbenro Beyioku, A.F., Fagorala, T., Abudu, O.O. and Galdanci, H.C. (2001) Prevalence of Trichomonas vaginalis in Patient with Vaginal Discharge in Lago, Nigeria. Nigerian Postgraduate Medical Journal, 8, 183-186.

[12] Kurewa, N.E., Mapingure, M., Munjoma, M., Chirenje, M., Rusakaniko, S. and Pedersen, B. (2010) The Burden and Risk Factors of Sexually Transmitted Infection and Reproductive Tract Infection among Pregnant Women in Zimbabwe. BioMed Central, 10, 127. http://dx.doi.org/10.1186/1471-2334-10-127

[13] Eddlesto, M., Davidson, R., Brat, A. and Wilkinson, R. (2010) Tropical Medicine. Sexual Transmitted Infection. 3rd Edition, Ch. 16, 598-600.

[14] Cook, G.C. (2010) Alimuddin I Zumla. Tropical Diseases, Ch. 81, 1421-1423.

\section{Submit or recommend next manuscript to SCIRP and we will provide best service for you:}

Accepting pre-submission inquiries through Email, Facebook, LinkedIn, Twitter, etc.

A wide selection of journals (inclusive of 9 subjects, more than 200 journals)

Providing 24-hour high-quality service

User-friendly online submission system

Fair and swift peer-review system

Efficient typesetting and proofreading procedure

Display of the result of downloads and visits, as well as the number of cited articles

Maximum dissemination of your research work

Submit your manuscript at: http://papersubmission.scirp.org/ 